\title{
Gestalt Couples Therapy in the Field of Trauma
}

\author{
Paul Jenkins \\ National University, San Diego, CA, USA \\ Email:drjenkins@sbcglobal.net
}

Received 6 March 2016; accepted 16 May 2016; published 19 May 2016

Copyright (C) 2016 by author and Scientific Research Publishing Inc.

This work is licensed under the Creative Commons Attribution International License (CC BY). http://creativecommons.org/licenses/by/4.0/

(c) (i) Open Access

\section{Abstract}

The field of Gestalt therapy has long had a troubled relationship with mainstream psychotherapy. The decades long assent of cognitive-behavioral and other, more objectively oriented therapies moved Gestalt even further from common acceptance as a valid alternative for treatment. Couple's therapy, in particular, has not commonly been seen as a natural "fit" for Gestalt practice. The author's view is that the recent rise of integrated therapy and the need for Evidence-Based Treatment separate from issues of allegiance to a particular school of therapy has created a new opportunity to reconsider Gestalt therapy theory and practice in couple's work. It is particularly relevant for work with couples in which one or both have been traumatized. Recent developments in Gestalt practice offers a fresh approach for such work, especially in regard to its focus on resolving underlying shame and the need for the couple to develop mutual acceptance at a deep level. Both these therapeutic tasks are vital in work with traumatized clients. These Gestalt tasks can easily be integrated with other, more mainstream models of working with trauma and working couples. An example of this integrated approach is offered to explore the ramifications of the theoretical assertion.

\section{Keywords}

\section{Gestalt, Couples Therapy, Trauma}

\section{Introduction}

The field of Gestalt therapy currently was currently experiencing a rather awkward relationship with what we could term "mainstream psychotherapy". From its very beginning, Gestalt therapy was in rebellion from the mainstream. Fritz Perls was deeply dissatisfied with the theory and practice of psychoanalysis as it then existed, and conceptualized a therapy approach that was much more experiential, less "theory laden”, and integrated the radical ideas of Gestalt psychology (Clarkson \& Mackewn, 1993). This new school of psychology emphasized 
the centrality of the individual's subjective creation of reality, based on the need to experience life through a holistic gestalt of otherwise chaotic, overwhelming data-points of sensory input (Saner, 1989). As a result of this emphasis, Gestalt's understanding of individual psychology leaned towards the post-modern, radical subjectivity perspective of the existentialists.

At the same time, mainstream psychotherapy was developing in a different direction. Behaviorism and clinical psychology (and even psychoanalysis to some extent) were more concerned with understanding externally derived, observable, "objective" factors in individual functioning. They sought empirically validated etiology and descriptions of specific "mental disorders", separated from the subjective individuality of a given client, as well as the establishment of empirically validated treatments for these "disorders". From the Gestalt perspective, mainstream psychotherapy was leaving the actual client further and further behind in its development of a mechanistic medical model for psychological problems. From the mainstream perspective, Gestaltists were "dreamy", unscientific, and leaving the real world further and further behind in its development of a subjectivistic model for psychological problems (Coleman, 1994; Schultz \& Schultz, 2012; Woldt, 2005). The separation of mainstream and Gestalt therapy is strongly evident in couple's as well as individual therapy. In Gurman, Lebow, and Snyder's (2015) Clinical Handbook of Couple Therapy, there is no separate chapter on Gestalt Couple's Therapy and only two references to Gestalt therapy in its 729 pages. Both were brief references to how Gestalt had been one of any number of influences on the author's work.

The question then becomes, if we have an interest in integrating the worlds of mainstream and Gestalt psychotherapy (an important question in itself), how do we reconcile these fundamentally different views of psychological reality? On the one hand, the postmodern approach says that all psychological reality is subjectively co-created in the interaction between the individual and certain aspects of the external world, which is perceived by the individual through the "filter" of his or her own processing, rather than the "objective" attributes of the external phenomena itself. On the other hand, the modernist approach emphasizes the importance of the attributes of the phenomena itself, and tends to view differences between them and the individual's perception as distortions, often leading to maladaptation or dysfunction. While to some, exploring and rectifying this difference may seem like an empty, philosophical exercise. It is, in fact, vitally important because the differences have driven the two worlds of psychotherapy apart and make it difficult for them to work together.

For instance, in mainstream clinical psychology, traumatic events are recognized as traumatizing in and of themselves, not because of the relationship between the event and the perceiver. Being sexually assaulted or grossly neglected as a young child is considered traumatic, aside from the subjective experiencing of the victim. Further, research has established certain common disturbances in psychological development that can be expected, given such trauma. To proponents of such knowledge and research, the Gestalt focus on the co-creation of reality leans dangerously close to blaming the victim. The client is suffering, not because of the trauma, but because of his or her relationship with the traumatic events; that is, their perception of and response to the environment. On the other hand, Gestaltists find it grossly mechanistic and infantilizing to see people as reacting like automatons to external events. We are all different, and have powers of choice and adaptation, that are ignored or rejected in the modernist, mainstream perspective. These different takes on trauma can lead to dramatically different positions on assessment, diagnosis, and treatment for individuals and couples struggling with these issues.

These differences are actually becoming more salient over time because of the emergence of two major factors in the field of psychotherapy. The first is the ascendance of integrated practice. At first glance, this may seem antithetical—shouldn't integrated practice lower the antagonism between different theoretical perspectives? In some ways yes, but the problem is that it has also served to cover up differences in belief and even suppress their discussion. In the past, there was certainly a lot of unproductive infighting between factions in psychology (psychoanalysis vs. behaviorism being, perhaps the most intense), but the positions were clear and out in the open, demanding that they be effectively developed and defended. Now, many reject the notion of even having a theoretical point of view, "I don't care how cars run, just tell me how to fix them!" But this atheoretical position has serious problems. First of all, how to properly fix a car is based on sound knowledge of how it works. You can memorize some steps to repair something, but the person who came up with those steps in the first place based them on a deeper knowledge of mechanics. And what if the steps don't work? What happens when the atheoretical, mechanistic approach to therapy goes off track? What will the therapist fall back on to try to get the therapy working? Also, therapists need to be conscious of their theoretical approach to trauma work-it drives what they think about their clients and what they think is needed to help them. A professor of mine once said, 
“Everyone has a theory of life. You can’t go through life without it. You can be conscious about it or not. It's better to be conscious, since it's going to drive everything you do anyway". Because of the relative lack of a strong theoretical foundation, integrated therapy can, all too easily, lead to thoughtlessness, unconscious bias, lack of "artfulness", and lack of depth in therapy.

The second factor is what is commonly called Evidence-Based Practice (EBP). This refers to the movement in the field to base our beliefs about assessment, etiology, diagnosis, and treatment on empirical research, rather than theory. Like integrated practice, this is a double-edged sword. On the one hand, it can help us be generally more efficient, effective, and reality-based. The history of our field is littered with ideas and treatments that, while well-meaning, were absurd and even harmful. Although each could be argued for or against on its individual merits, I would include Primal Scream Therapy, EST, and LSD Therapy in this list. By the end of the eighties, it could well be argued that the field needed a better grounding in empirical research-what is really true and what really works. By the way, on a personal note, I became a proponent of EBP as a child while watching an episode of the Phil Donahue Show, where a psychotherapist explained how all of his patients had "spontaneously discovered” memories of being abducted by aliens, which turned out to explain all their psychological problems!

On the other hand, there are severe problems with EBP. These include the gross limitations of the scientific method to explore psychological issues (for instance, we can only study what can be measured-thus the immense number of studies involving observable behavior and paucity of studies involving the feeling of love) and the increasingly restrictive effect it has on professional practice. Once we have identified a "correct understanding” of a phenomena and its treatment, that becomes what is "acceptable” and then "required" in practice. Thinking or doing anything different becomes suspect and then prohibited. Approaching things differently changes from being flexible, artistic, unique, or innovative, and becomes unethical, illegal, and un-reimbursable. The last point is particularly important, because the issue of breaking the law will affect only a narrow range of practices and practitioners, but the issue of what people/institutions will pay for is far more pervasive and "shaping" of what is acceptable within a modernist, mechanistic viewpoint. On the other hand, the postmodern, subjectivistic viewpoint is much more accepting of a variety of ways of understanding pathology and approaching treatment as legitimate (Gergen, 1991, 2009, 2011; Lewis, 2009). Without a rapprochement between the two, practitioners of the Gestalt mode are at risk of being considered unprofessional, unscientific, unethical, and ultimately refused reimbursement for their services. At this point, I am not aware of any jurisdiction attempting to make the practice illegal, but given the increasing intrusion of civil law into matters of psychotherapy (reporting requirements, legal issues involving age of consent and scope of practice, allowance or disallowance of sexual orientation therapies) it may only be a matter of time.

To summarize, mainstream psychology tends to be modernistic/mechanistic, while Gestalt tends to be postmodern/subjectivist. The conflict between these foundational approaches has led to a number of as current and emerging challenges. Gestalt therapy needs to evolve if it hopes to retain relevancy and acceptance within the wider world of mainstream psychotherapy, increasingly dominated by EBP. To do so, it must integrate the empirical findings from various other areas, including neuropsychology, the study of complex trauma, developmental psychology, and couple's therapy. The purpose of this paper is to lay the foundation for, and provide an example of such an integration, at least in an introductory way. The basic question asked here is, "how can information and concepts from mainstream psychology be integrated with Gestalt practices and principles to enrich our clinical work with couples where at least one has experienced significant complex trauma”. To answer this question, the paper will first create a conceptual foundation to support the integration of Gestalt theory, practice, and information from other clinical fields. Then it will present a brief review of related common practices and principles from mainstream psychotherapy. Finally, it will present a case review that reflects an integration of mainstream and Gestalt theory and therapy.

\section{Conceptual Foundation}

As noted previously, the Gestalt perspective is based on a relativistic understanding of human mental functioning. What we perceive and re-cognize as reality is a flowing, continuously emerging Gestalt of various streams of information that gain their valence, quality, and specific, as well as general meanings from their relational matrix (Parlett, 1991; Wheeler, 1991, 2000). In other words, we are the creators of our reality-not the passive receivers of objective "truth". While specific elements of the objective world may be understood as "real" (the 
tree falling in a forest does create sound waves, whether or not a perceiver is there to "hear" it), those elements carry little to no meaning outside their relationships with each other (Herman, 2013; Horrigan, 2007). This is what is fundamentally meant by the "field perspective" in Gestalt psychology. In understanding this process, we can subsume seeming contrasts, dualities, and even the seemingly objective "truth of things" under the fundamental unity of experienced, subjective reality. The importance of this perspective cannot be overstated. Perls himself pointed out the centrality of the issue when he wrote that taking a unified "Gestalt mentality" guides us to an "original, undistorted, natural approach to life" (Perls, 1951: p. 14). An implication of this idea is that a holistic and relativistic approach to human experience not only is a more valid theory of human nature, but has important clinical implications for helping people lead more fulfilling, energized lives.

However, as noted previously, the kind of extreme subjectivism or relativity implied in Gestalt theory and practice is problematical for mainstream psychology. This is where the question of rapprochement enters the picture. Can the conflicting views of modernism and postmodernism be integrated, or at least peacefully coexist? Again, this is not just a philosophical point, but has real-world consequences for what is considered professional, ethical, and reimbursable practice. What is proposed here is that peaceful coexistence is possible. The way forward is to grant that both approaches to conceptualizing reality (objective and subjective/concrete and relativistic) are, in fact, valid.

For example, think about light. What is it? What is its core reality? This was quite a mystery for a long time (Zajonc, 1993). As the reader no doubt knows, it was discovered that light is a form of electromagnetic radiation that exhibits properties of both waves and particles. This is, ironically, known as wave-particle duality. It turns out that, under certain conditions, for certain purposes, light is a wave. Under other conditions, for other purposes, it acts as if it is made up of particles. So, on the one hand this example upholds the basic premise that relational dynamics are dramatically important, but on the other hand, it establishes the fact that things do have a separate existence, which can manifest itself in different ways, given different field conditions. No physicist would say that light is an academic abstraction that does not exist separate from its relationship to a perceiver, but they would insist that how it is experienced and how it behaves is relative to the experiencer, given different conditions and purposes. In other words, quantum physics is real, but it didn't sweep away the Newtonian laws of physics. They both exist side-by-side, equally valid, but useful in different ways, in different contexts, and for different purposes.

Therefore, one way to approach the difference between the modernist and postmodernist approach is to think of it as a micro versus macro understanding of the given Gestalt of a situation. At the micro level, "things" can be studied, and their qualities known, in and of themselves. At the macro level, processes and relationships are explored, based on a better knowledge of the underlying specific elements. An example of this approach is found in engineering. The tensile strength of a specific metal needs to be known before it can be utilized in the plans for building a structure, which then requires an understanding of how that tensile strength will related to the overall design. Further levels of relationship can be explored, including the connection between structural design and aesthetics, how the building will work within the qualities of its immediate social and physical environment, and how the energy efficiency and intended purposes of the building fit with the needs and values of the surrounding culture or even the planet. In this example, micro and macro level "lenses" are not mutually contradictory, but are, in fact complementary. It does the engineer no good to treat construction materials as unimportant abstractions. Instead, she is best served by a solid understanding of both the concrete and the relational. What is being suggested here is that objective/subjective is a natural polarity, not a duality. Rejection of the objective, in favor of the subjective (or the individual, in favor of the collective) is itself a duality.

This distinction between what we might call contingent (polarity) and radical (dualistic) field theories is important if Gestalt is to find a rapprochement with the rest of psychology. To do so, it must include a shared perspective on what constitutes basic truth in regard to psychological reality. While Gestalt thinking about field theory has a tremendous amount to offer other psychological disciplines in softening their overly dualistic/objectivist/mechanistic perspectives, if it goes too far, it will fail to find "common ground", simply argue for one "side" of a duality over another, and stay on the outside, looking in with mutual judgment and rejection. Contingent field theory provides such a common ground, so we can ask questions that are mutually relevant to both Gestalt and other psychological disciplines. In any given clinical situation, what are the knowable, concrete facts? And how are they embedded in a relativistic field of lived experience?

This has direct ramifications for trauma and couple's therapy. For instance, when sitting with a couple, it may be necessary to objectively evaluate the concrete truths in their lives. If one of them has been hit by a car and has 
significant brain damage as a result, the therapist needs to take this as an objective truth with very real, knowable consequences for neuro-psychological functioning. On the other hand, there are major elements of the clinical picture that are relativistic in nature. What is this client's "relationship" with her sense of "damage"? How does she see herself as "changed"? How does this fit within her given culture's ideas about her as a woman, a wife, a mother, a worker, etc.? And very importantly, what is her partner's "relationship" to this damage? There is no doubt that the brain injury is part of, and helps structure the field of this couple's reality. At the same time, it represents a mechanistic reality that doesn't go away, and is best confronted based on its objectively true conditions. In other words, the brain injury is a concrete reality embedded in a relativistic field that has important ramifications for the life of the couple.

\section{Gestalt Treatment of Trauma and Couples}

Gestalt therapy holds an interesting and, at times controversial place in the history of theory and therapeutic practice as it regards trauma and working with relationship problems, especially in couple's work. As is well known, Gestalt practice developed in a way that focused on the individual and was extremely subjectivistic. Because of this, and its emphasis on the "here and now", Gestalt process tended to deemphasize etiology or exploring the past to understand and disentangle the roots of current relational problems. Certainly there was talk of "unfinished Gestalts" and "baggage", but Perls and many of the practitioners who followed were leery of letting, or worse, encouraging clients to spend time fixating on the past and blaming others, which could lead to increased resistance to being in the "here and now" and taking personal responsibility for current situations and current solutions. The "treatment" focused almost exclusively on increasing immediate experience of the individual self, whether the format was individual, group, or couples counseling. This approach has been criticized and subsequently modified by a number of writers/practitioners in recent decades, and has led to a profound evolution in the theory and practice of Gestalt couples counseling (Backman \& Wheeler, 1994).

The primary goal of Gestalt couples counseling is to increase the quality, ease, and frequency of exchange between the partners in the couple (Wheeler, 1994). To the extent this happens, the partners become more present, alive, and aware, thus better connected with each other while retaining, or even increasing their respect for their separateness (Borofsky \& Borofsky, 1994). This point is reinforced by Wheeler (1994) when he asserts that Gestalt therapy is "inherently and necessarily relational in its theory and methodology" (p. 31) and that intimacy itself is a primary need of all individuals. Together, these points make it clear that the newer approach to Gestalt work, especially with couples, makes a break from the older, more individualistic conception and practice of Gestalt. Rather than focusing on the individual, who may, by chance make contact with another, it iterates that healthy intimacy is a central part of growth of the self. In other words, good interpersonal relationships are not just the outcome of individual development, but a central component of healthy development. This reorientation of relationship process from the periphery to the center of Gestalt therapy has important ramifications for such work with traumatized couples.

In the past, there would likely have been a focus in the Gestalt couples work to, in a sense isolate the processing of each individual's trauma, separate from their dynamics as a couple. They may have been asked to "take turns" in the "hot seat", working through their individual "unfinished business". The work, as it has been transformed, now focuses on how trauma manifests itself within the relationship itself. Still focusing on the "here and now", the therapy explores how the trauma has not been assimilated and remains an "active and distorting presence" (Geib \& Simon, 1994) in the relationship. Some of the primary dynamics to consider within this approach include how the effects of the trauma inhibit contact, confuse past and present realities, and lead to disruptive levels of shame. The primary therapeutic process would be to support the couple's mutual creation of meaning. To do this, the therapist actively directs and supports a series of relational experiences, with the general goal of greater knowledge of self and other. This is in contradistinction from some other approaches, which attempt to train the couple to engage in supposedly more functional ways to communicate and behave. The underlying philosophy of Gestalt therapy is still fundamentally humanistic in nature, trusting that self-knowledge leads automatically to greater self-determination, thus better problem solving, more adaptive choices, individual freedom, and ultimately higher levels of joy, peace, and satisfaction. In other words, the focus is still on the process of couple's therapy, rather than making specific changes in the couple's behavior.

One area that requires further explanation is the particular importance of shame as it relates to trauma and interpersonal relationship. For many years, psychodynamic theory and practice asserted that anxiety was the pri- 
mary emotion associated with early childhood trauma and subsequent personality formation and relationship dynamics. Without getting into too much detail (which would require a separate paper), the basic conception was that the innate drives and emerging wishes of the individual come into conflict with external reality (including other people) and the developing superego, leading to more or less chronic and unconscious anxiety, which creates, not only individually experienced suffering, but disruptions in one's relationships (Freud, 1920). This was seen as a basic reality for everyone, under the best of circumstances, but was much more extreme and disruptive when the individual had experienced early childhood trauma.

Newer thinking in Gestalt circles has reimagined the dynamic of early childhood development and come to the conclusion that a much more common core emotional problem revolves around shame (Backman \& Wheeler, 1994; Lee, 1994). The basic idea here is that shame is more than just an emotion, it reflects anorganismic drawing back when one perceives the environment as unsupportive of his or her wants, needs, or basic beingness. It serves a vital self-protective purpose, recognizing inadequate environmental support and regulating the expression or even experience of desire and needs. As such, shame reactions are unavoidable in an imperfect world, however, when there has been experiences of developmental trauma, shame can become ubiquitous, dysfunctional, and hyper-reactionary. Kaufmann (1989) describes the process whereby children, through multiple shaming experiences (trauma), can end up linking shame to various needs, feelings, and even their entire sense of being. The result can be a general sense of alienation, inferiority, and restriction of self. This restriction becomes both a self-fulfilling and reinforcing dynamic as it limits access to information about the self and others, and drives impulsive counter-measures to avoid the more painful direct experiences of shame. Relationships can embody a horrific cycle of unconsciously seeking out shaming others, then reacting counter-productively when shaming attempts are made by them.

When both partners are trauma-driven, there may be deeply reinforcing patterns of conflict, conflict avoidance, mutual shaming, and counter-shaming. Lee (1994) called this, "the systematic interaction of the two partner's respective shame issues" (p. 271). The remedy, from the Gestalt perspective is to aid and support the process of developing self-knowledge. In some ways it is indistinguishable from individual therapy, but with the profound difference that it is not just individualistic, but includes developing knowledge of the other and knowledge of the relational dynamics of the couple that arise from their respective individual selves in contact with the other. It is the idea of contact within the interactive and mutually created field of relationship that places Gestalt in a unique position to effectively assist with relationship problems arising from trauma.

Other Approaches to Trauma and Couples Therapy

The history of assessment and treatment of complex trauma goes back to the early days of Jean-Martin Charcot (van der Kolk et al., 1996b). However, throughout the years since, both the concept and proposed treatments for this problem have gone through as many reformulations as there have been psychological schools of thought (Curtois \& Ford, 2009; Herman, 2009; Kepner, 1995; Kerr, 2003; van der Kolk et al., 1996a, van der Kolk, 2014; Wiger \& Harowski, 2003). At the turn of the $20^{\text {th }}$ Century, Freud reconceptualized childhood trauma and its psychological consequences as stemming, primarily from the intrapsychic conflicts of the client, rather than the natural outcomes of various types of abuse or neglect. Later in the $20^{\text {th }}$ century, psychodynamic revisionists that included a number of theories, including attachment theory, object relations, self-psychology, and interpersonal theory, all returned to the primary etiology of childhood trauma being the trauma itself, not the intrapsychic failings of the victim. There was a reactionary period during the 80's and 90's when it was virtually "forbidden" to suggest either 1) the level of negative consequences from trauma was related to preexisting resilience or vulnerabilities, or 2) the victim could continue to "recreate" the trauma in his or her life and therefore have some culpability for ongoing problems. Since then, there has been increasing integration of theories and findings from various schools of thought in the field regarding etiology, assessment, and subsequent treatment.

For instance, attachment theory has expounded on the inherent need of infants and young children to seek support and "connection" to primary caregivers, how that need and subsequent personality of the developing child is shaped by the actual care giving qualities of its parents, and thus what kind of therapeutic interventions will be most effective to change dysfunctional interpersonal dynamics for a traumatized client (Courtois \& Ford, 2009). Object relations theory helped provide a framework for the concept that more or less healthy aspects of the developing "self" are internalized through the intense enmeshment of child and caregiver in the first few years of life. These internalizations form the core of self-concept and in the context of trauma, lead to highly negativistic and unhealthy personality formations and thus dysfunctional interpersonal dynamics. Humanistic theory focuses on the inherent drive for mastery, psychological health, and integrated functioning, or what is 
generally referred to as self-actualization. To the extent that this drive is central to "normal" development, then some form of traumatization is required to explain deviance from that drive-goal. This suggests that intervention should focus on aligning with and supporting the self-actualizing potential of the client against the traumatizing influences of childhood. Other models, such as cognitive-behavioral and solution focused therapy have deemphasized the etiology of trauma in favor of working on "fixing the problem as it exists now" and helping the client adjust their thoughts, feelings, and behavior in order to maximize interpersonal skills and thus be able to form and maintain more stable and satisfying relationships. Other authors have even explored specific neuro-developmental psychological processes and how they are damaged by early childhood trauma, leading to relational difficulties and ramifications for treatment (Siegel, 1999, 2007).

There has been surprisingly little work in regard to specific treatment recommendations for traumatized couples, with much more research and clinical work focused on either individual or family therapy. That being said, some researchers and clinicians have paid attention to this under-attended population of clients (Gurman, 2015). For instance, Johnson (2002, 2009) has developed an approach she calls Emotionally Focused Therapy (EFT). Identifying the main impacts of complex trauma on self-identity, self-worth, relational prototypes, and emotional regulation, she concludes that couple's therapy is an important approach when one or both partners have such a history. Given the damaging effect of underlying trauma on relationships, she agrees with Wheeler (1994) on the relevance of addressing such problems within the context in which they manifest themselves. The therapy itself focuses on the self of each partner, the relational system, and how partners construct their experiences and patterns (Johnson, 2009). So far, this description is not dissimilar to the theory of Gestalt therapy with couples outlined by Wheeler and others (1994). Where it moves in a different direction is in its focus on certain specific interventions seen as needed to address the specific challenges of working with this population. For instance, Johnson proscribes active intervention to deescalate negative cycles, restructure negative interactions into positive ones, using evocative questions and interpretations, and privileging emotional responses. The last intervention listed is central to the therapy (as its name would suggest), because emotion is seen in this model as the main information processing system that communicates needs, desires, meaning, and motivation to the self and to others, thus supporting self-esteem if it is effective and causing significant problems when it is not. The meta-goal of EFT is to shape more positive cycles of connection and a more secure attachment bond. Again, this is a more concrete, action-oriented goal than in Gestalt where the focus is on greater self-awareness, which is trusted (reflecting its humanistic roots) to lead more or less automatically to higher functioning.

Even within the specific field of couple's therapy, relatively little has been written about trauma. For instance, John Gottman is a major figure, both in terms of research and treatment. In his major textbook on the subject, The Marriage Clinic (1999), he dedicates only two pages to the subject of trauma. It is briefly mentioned in regard to assessment of a couple, it is dealt with in a little more detail when discussing various exercises couples can do to enhance the marital friendship. Gottman (1999) suggests that a traumatized partner write about his or her experience of trauma, how it has affected them, how they have coped, etc. The purpose of the exercise is to deepen the knowledge and understanding of the partner's history and its implications for their relationship. Each person is to write their answers to the various questions in a notebook, and the partner reads it and they talk it over.

Returning to trauma-specific therapy, Briere (2002) advocates for an integrated model of treatment. He utilizes his self-trauma model to incorporate aspects of trauma theory, cognitive, behavioral, and self-psychology. The basic premise is that posttraumatic reactions are not just clinical symptoms but reflect a psychological mechanism that serves the function of reactivating and processing traumatic memories so that they can lose their distressing properties and be effectively handled by the person's existing strengths or abilities. The therapy approach he advocates is based on cognitive-behavioral principles, but also incorporates other elements. While it does not specifically address work with couples, the basic principles he describes are applicable to couple's therapy and serve as a basis to compare and contrast with a Gestalt approach to clinical work with this population. One of the main principles that Briere ascribes to is the idea that the therapy should be carefully modulated in order to avoid the client/s becoming overwhelmed, thus reinforcing trauma reactive avoidance strategies (2002). In order to do this, the therapist can shift from exploration of material directly related to the trauma to consolidation (support previous gains) as needed to externally regulate the intensity of the process. Another tactic to regulate intensity would involve carefully timing interventions so that there is low intensity at the beginning and ending of each session, with the highest intensity work occurring in the middle. A third tactic involves goal sequence, with assessment and development of self-resources and coping skills coming first. This is considered vital be- 
cause too much exposure to traumatic material can easily lead to fragmentation, dissociation, later engagement in dysfunctional tension-reducing activities, and even therapy drop-out. Other interventions considered important include the ongoing provision of safety and support during treatment, the facilitation of self-awareness and positive identity, the development of healthy interpersonal boundaries, the development of affect regulation and tolerance skills, and improved relationship functioning.

The last issue, improving relationships, is particularly important in regard to this essay. Briere (2002) stresses the importance of interpersonal difficulties as a common feature of abuse survivors. In his self-trauma model, he focuses on how traumatized clients tend to develop negative attachment schema and habitually engage in relationship patterns that recapitulate the original pattern of trauma. While the self-trauma model understands this as repeated attempts to "work through" the problem, Beire recognizes that in many cases, it is not getting worked through, and is manifesting as chronically disturbed interpersonal relationships that are often the focus of therapy, and will present itself in the relationship with the therapist. For that reason, he supports therapeutically working on trauma within the relational context in which it lives. While, to this purpose, he focuses on the relationship between client and therapist, it is likely that he would support such work in the context of couple's therapy as well. The bottom line here is that, on the one hand, Briere accepts that the effects of trauma reach deeper than the typical goals and techniques of cognitive-behavioral therapy, honors the natural drive for individuals for wholeness and healing, and requires that the therapy focus on relationship dynamics both inside and outside the therapy room. This is consistent with the Gestalt perspective. On the other hand, he advocates for a number of interventions that are quite directive, “top-down”, and include specific skill-building. These are not naturally consistent with a Gestalt approach.

Bischof \& Helmeke (2003) advocate for treating serious individual problems in the context of couple's therapy. They make the point that couples seek homeostasis, thus a partner is apt to adjust to the psychological problems of the other and may even resist the healthy change of his or her partner if it occurs in the context of their individual therapy. For instance, individual who has been traumatized and as a consequence tends to distance and even dissociate may be with a partner who is comfortable with that, and reacts badly when he or she begins expressing more emotions or opinions. This can lead to attempts to "change the partner back" or get them to end therapy. In any case, it can typically lead to an increase in interpersonal stress in the relationship, not less.

Basham \& Miehls (2004) are clinical social workers who take a more multi-cultural perspective than many clinicians. They emphasize the importance of the cultural context of how traumatic events are understood and commonly dealt with by individuals and couples. Partly because of this, they advocate for utilizing a wide variety of theoretical perspectives in assessing the clinical needs of a traumatized couple, including trauma theory, attachment, object-relations, cognitive-behavioral, etc. In regard to treatment, they propose synthesizing multiple models and techniques of therapy, and implementing a three-stage model. The stages include 1) safety, stabilization, and establishing the context for change; 2) reflection on trauma narratives; and 3) consolidation of new perspectives, attitudes, and behaviors. The three-stage model provides the foundation, while they synthesis of theories and techniques offers the greatest flexibility to meet the clinical needs of any given couple. This structured but basically integrated approach is deemed necessary, not only because different cultures "frame" trauma differently, but each individual couple presents with a unique set of strengths, challenges, therapeutic goals, and clinical needs.

In an unpublished paper, Fisch (2014) makes the point that most models of couples counseling do not consider the unique impact of trauma on the individuals and relationship dynamics within these couples. Like other writers, she notes that complex trauma in childhood is particularly disruptive of later relationships because of its negative effects on emotional, cognitive, and psychological development. Three common patterns she identifies in these couples include the tendency to experience: 1) chronically high levels of emotional hyperarousal; 2) chronically low level of arousal (hypo); or 3) one partner experiences hyperarousal, while the other is withdrawn or emotionally inaccessible (hypo). Any of these three patterns reflects a dysregulated state that disrupts the ability to adequately process their interpersonal problems, complete "repair attempts" after arguments, and enjoy a generally stable, flexible, or adaptive relationship together. Like Basham and Miehls, Fisch recommends utilizing a three-phase treatment approach, in which the first task is to establish safety, stabilization, and symptom reduction. When this is adequately completed, the couple is ready to work on remembering and processing the trauma. Finally, integration can occur, where the couple is helped to bring awareness to the positive changes in their behavior, emotional lives, and beliefs, and incorporating these changes into their overall sense of self, relationship, and the world in general. While she does not advocate for any particular therapeutic approach, such as 
Gestalt, Fisch does mention that establishing and maintaining a positive therapeutic relationship with traumatized couples is particularly challenging, yet vitally important.

Mazor (2004) approaches therapy with traumatized couples from an object-relations perspective. His work with adults who were children during the Holocaust led him to a number of conclusions. First of all, he found that his clients had tremendous difficulties in their intimate relationships. Their traumatic experiences had damaged their capacity for intimate partnership in the areas of love, passion, sexuality, and mutual friendship. He found that these problems were related to the extensive use of repression, splitting, and dissociation to deal with the trauma. These defenses lead to difficulties remembering the trauma and its psychological impact, emotional reactivity, and a focus on blaming the current relationship for problems rather than the original trauma. The therapy itself attempts to differentiate "destructive inner representations" of the past and current struggles in the relationship and perceptions of the relationship's history. The therapist's role is to decipher and reconstruct a new space that symbolizes and contains the partner's object relations deficiencies, thus changing their projections. In other words, the therapist identifies and reframes distorted representations that developed in the relationship, based on early traumatic experiences. Over time, the couple learns new, more flexible modes of responses and behaviors.

\section{Integration}

In the first century of formal psychotherapy (roughly 1890 to 1990) there was a tendency for therapists to break into separate and often antagonistic schools of thought (Hunt, 1993). There were psychoanalysts, behaviorists, humanists, and many sub-schools or splinter groups, including Gestalt, which is typically considered a subgroup of humanists. However, as we move firmly into the second century of this field, there is greater interest and activity in the integration of various theories and methods of psychotherapy. The Common Factors movement, which has been part of this change as research in psychotherapy, has found that psychotherapy effectiveness has relatively little to do with particular theoretical approaches to treatment but more with a set of client and therapist qualities that can be common to any particular approach to therapy (Drisko, 2004). It is becoming increasingly difficult to be considered an open-minded, unbiased, and ultimately professional and effective practitioner without taking into account and acting upon various ideas, findings, and techniques that are applicable to a particular client, and not be too focused on one particular theory of psychotherapy.

This is as true for couple's therapy as it is for individual work. Many ideas and practices have been developed for work with couples over the years, and in some ways Gestalt is relatively late to the game, for reasons discussed at the beginning of this paper. But that does not mean it has nothing meaningful to add. In fact, the field perspective that is at the core of Gestalt is perfectly suited for work with couples. More than in individual therapy, it can be said that couple's therapy is all about the field. How do the partners stand in relation to each other? How does one partner effect the other? What happens when a third element (the therapist) is added to the field? And how does a history of complex trauma for one or both partners effect these dynamics? Approaching these questions from a field perspective is actually quite logical and natural.

One of the unique characteristics of couple's therapy, as opposed to individual therapy is the lack of clear goals. If an individual client presents herself with major depression and a history of suicide attempts, at least some of the focus of therapy is immediately clear. Decreasing risks and symptoms will, by ethical and moral necessity, be part of the treatment. On the other hand, just what is functionality in a couple? Should a couple breaking up after participating in couple's therapy be considered a failure? An individual client's suicide after therapy certainly would, but in many situations in couple's work, the ending of an unsatisfactory relationship may be considered a success. Much more could be explored about this but the main point is that effectiveness in couple's therapy is not as easy to conceptualize or plan for, as it is in individual therapy. So, without clear "goal-posts" for success, the field perspective offers a particularly relevant, useful, and theoretically coherent approach.

The main strengths of the Gestalt approach to this work are its intense focus on the constructivist model of experience, the emphasis on working within the context of the problem, the position of the therapist as a facilitator of the process, the focus on general goals (presence and awareness, leading to better connections with others) rather than specific outcomes, and the emphasis on issues of shame as central to relational problems and their ultimate solutions. The primary role of the Gestalt couple's therapist then is to facilitate an exploration of the co-construction of the couple's experiential reality, identifying and working through patterns of shaming and 
being shamed within the context of the traumatized self, and thus leading the couple to a higher quality, ease, and frequency of exchange in their shared relational field.

Research and clinical experience from other perspectives provides important information and suggestions that can aid Gestalt work with traumatized couples. Object relations and attachment theory informs us about the specific ways that early childhood trauma effect the developing relational dynamics of an individual; how they see themselves and others, how they behave to protect themselves and get what they need. Briere's work reminds us how traumatized individuals often recreate their patterns of abuse, not just because that is their existing pattern of relating to others, but also because they are trying, at some level, to work through and master their painful pasts. He also reminds us that therapists have a responsibility to modulate the therapy, keeping it from being too intense for a traumatized individual or couple to handle, but intense enough for effective work to occur. Also, there is the point that while non-directive therapy is good, traumatized individuals (and by extension, couples) need to develop specific skills related to affect regulation and interpersonal relations. Whether they describe a multi-stage therapy (Fisch), advise using specific interventions to deescalate negative cycles, restructure negative interactions, and privilege emotional responses (Johnson), or teach mindful awareness to develop an integrated self and improve interpersonal relationships (Siegal), these therapists advocate for a more directive therapy than is typical in Gestalt work.

Therein lies the main difference. Given its Humanistic roots, Gestalt tends to follow the core belief that there is a natural tendency for the human organism to "grow" in the direction of health, functionality, and intimacy, if the conditions can be established for that growth to occur. It is the job of the therapist to create and maintain those conditions, not aim for a specific outcome in the therapy. Ironically, few if any of the authors cited in this paper would disagree with that foundational belief. They might say, however, that when dealing with traumatized individuals, the developmental disruption is so severe that those clients require more active, directive, "repair" oriented interventions than would be necessary for higher functioning clients or couples.

This leads to the concept of integration. As noted earlier, the field of psychology is moving towards combining different therapeutic ideas and techniques in unique ways to meet the needs of different clients. We have explored the basic principles of the Gestalt approach, as well as various others, and there is little that would make them incompatible. The key is for Gestalt to embrace what we are calling contingent field theory, which retains the core of the constructivist model of experiential reality, but also allows for accepting a more "objective" view of phenomena, depending on whether one is taking a micro vs. macro perspective. For instance, a therapist can take a fundamentally phenomenological approach, yet recognize the importance of specific, objectively oriented factors, such as the neurological impact of childhood trauma on memory and affect regulation, or the clinical value of implementing stages of therapy, actively regulating intensity, and teaching specific skills. In the same way that a psychodynamic therapist may, at times utilize cognitive or even behavioral interventions, Gestalt therapists can "borrow" from other approaches to meet the specific needs of their traumatized clients. On the one hand, Gestalt field theory is highly valuable as the "organizing principle" in couple's therapy (and perhaps to integrate the entire field of psychology) but, it should be noted, it would be best served by resisting taking its subjectivity to extremes and accept the growing body of "objective" clinical knowledge that surrounds it. The result would be Gestalt practice that is potentially more effective, more aligned with principles of evidencebased practice, and thus more "acceptable" to "mainstream" psychology. While this is certainly not everyone's goal, to the extent Gestalt practitioners would like to end the perception that they are "on the fringe" or worse, irrelevant to modern psychology, it will need to embrace multiple theories, approaches, and techniques. Gestalt has an important role to play, emphasizing the experiential element in therapy, and pointing out the ultimate phenomenological and relativistic nature of any and all conceptions of mental health and mental illness.

\section{Praxis}

Tom and Carol came to therapy after 15 years of marriage. Tom was in his early sixties and had been married before, with one child from that relationship. Carol was nearly twenty years younger than Tom and the couple did not have children of their own. They presented with problems related to sexual intimacy, frequent fighting, and feeling like they had generally "grown apart". They initially agreed, for the most part, regarding what their main problems were but, not surprisingly, had different ideas about what had led to them. Tom saw the main issue as his advancing age. He said that he did not have the same energy or patience that he used to have as a young man. Carol reported significant changes in their relationship over time, related to her becoming the primary breadwinner, Tom becoming increasingly dependent on her, and the two of them becoming isolated from 
friends and family they used to be close with. It became clearer over the first couple of sessions that Tom was becoming much more isolated than Carol. They had moved to a rural part of the state, he was unemployed, and spent much of his time hanging around the house, driving into town to do errands, and working on a book, which seemed to be taking a long time and not getting anywhere. Carol had become an executive and spent a great deal of time and energy with her work, both at the office and at home. This was a profound change for them, since when they first met, Tom was the breadwinner and Carol was a very young woman with no professional path. In fact, as the work progressed, it was discovered that Carol had been sexually abused within her family as a child and when she met Tom, experienced him as a strong, mature man who could quickly save her from her family situation and set her up in a secure, financially comfortable new situation. He could take care of her, support her, and protect her from further abuse. For Tom's part, he had been raised by an angry, aggressive father and a rather passive, asexual mother. He experienced Carol as a beautiful, vivacious, intelligent, assertive young woman who could fit in well with his lifestyle and friends. He had also recently experienced the breakup of his first marriage, with a woman who had had a "mental breakdown", been psychiatrically hospitalized, and spend a number of years tormenting him with paranoid outbursts and accusations. Emotionally traumatized by this, Tom finally filed for divorce, with intensely mixed feelings regarding the "abandonment" of his "sick" wife and mother to their child. Tom reported that he also saw Carol as being, potentially, a much better mother figure for his young daughter.

It became clear that each had found, in the other, a "fix" for their trauma. Carol found, not only a better, non-abusive father, but also a ready-made family which would demand little of her, other than to be pretty and charming. Tom found an "emotionally safe" partner who was sexual and assertive, and would let him be strong and in-control without having to be angry and aggressive like his father. Like many couples, they had found "the perfect partner" in one another that served as a counter-point to the earlier abuse they had experienced. Sadly, as happens so often, over time, this "solution" ended up being far less than perfect and even recapitulating of the very abusive dynamics it was meant to avoid. In the case of Tom and Carol, over the years, Tom had become increasingly dependent on Carol, leading back to his fears of being "emotionally abused" by a powerful other. As she became more frustrated with Tom's lack of productivity, Carol became angrier and asexual, triggering Tom's traumatic reactions to his father and mother. As Carol became more mature and powerful, in her own right, she saw Tom's passive-aggressive attempts to control her as abusive and reminiscent of the kind of "mind games" her sexual abuser would play on her to get what he wanted. These dynamics were self-reinforcing, leading to the increase in arguing, sexual problems, and general interpersonal distance.

By the time they sought therapy, Tom and Carol had become entrenched in an intense shame cycle. Each defended against shaming by the other by engaging in "shame attacks" themselves. Tom would regularly criticize Carol's working too much, her lack of sexual interest, and her lack of help at home. Carol would counter-attack by criticizing Tom's joblessness, his lack of progress on his writing project, and the poor quality of his housekeeping. The image that emerged for the therapist was that of two injured warriors, hiding within deep bunkers, lobbing emotional hand grenades at each other, blaming each other for the war. Each had been repeatedly attacked and shamed over the years by the other, to the point where mutual trust was in tatters. With little trust in place, real intimacy was impossible.

As the therapist assessed the situation over the first couple of sessions, a treatment plan slowly emerged, based on an integration of Gestalt and mainstream approaches to trauma and couples counseling. From the Gestalt perspective, it was clear that there was an escalating shame cycle at work, which was grounded in their original traumatic experiences in childhood. According to Lee (1994), "shame often can't be seen directly. Rather what stands out are the defensive behaviors that people use to camouflage and attempt to escape their experience of shame" (p. 263). This was quite true for Carol and Tom, so a goal was discussed and agreed to, to increase their verbalizing when they felt shame in their interactions, rather than react defensively. They also agreed to become more cognizant of when they were trying to shame the other, often in reaction to feeling shamed themselves.

Perhaps better understood as an "unfinished gestalt", both Carol and Tom had a history of trauma that had not been assimilated and thus persisted as an active and distorting force in their relationship. It continued to inhibit their ability to make direct contact with the other, apart from each partner's trauma induced "ground". A main goal of the therapy became, therefore, to help each to confront the reality of their traumatic history, recognize how it had impacted their current relational dynamics, and work through the cognitive and emotional consequences of the trauma, in the field of their current relationship with each other. In practical terms, what this 
meant was that Tom acknowledged that his "unfinished business" with his father had led him to become passive-aggressive in relationships, rather than assertive. He had to learn how to overtly assert his desires and needs in his relationship with Carol. For her part, Carol had to learn that she could be strong, without needing to reject the other, as she had learned through her experience of sexual abuse. Luckily for both of them, the seeds of their relationship problems also carried the germ of change. Tom's anti-dominating attitude about masculinity made it easy for him to let Carol be strong without feeling emasculated and Carol's sensitivity to being dominated made it easy for her to appreciate Tom's lack of masculine domination. These potentials for healthy change were tapped through Gestalt style communication exercises, increasing both partners' willingness to express truths that had not been given expression before.

From a more mainstream point of view, the therapy focused rather heavily on Tom and Carol's underlying emotions, regarding themselves, their past trauma, and each other. The experience and expression of these emotions was encouraged, supported, then worked through along the lines described by Johnson (2009). This was done by focusing on the concept of affect regulation, that is, how were Tom and Carol individually and collectively controlling, experiencing, and communicating their emotions. By overtly exploring these questions in front of each other, the couple was able to develop a better understanding of and thus empathy for: 1) the source of the other's troubling emotions; 2) the struggle to control them; 3) the distortions in their communication. As a result of this process, both partners found better ways to deal with their emotions, in relationship with each other. For instance, each learned to identify negative emotional reactions to the other as largely grounded in their traumatic past and thus take more personal responsibility for them, rather than blaming the other for causing them. This made their conflicts much more productive and less harmful.

Another "mainstream” technique that was used was John Gottman's use of writing about trauma. Tom and Carol both wrote a short note to the other, describing their experience of trauma, how it affected him/her, how it has impacted his/her relationships, and how he/she hopes to recover. They then shared these notes with each other in therapy and discussed their reactions. This took place over two sessions and was, perhaps, the most intensely useful techniques in the therapy. Implemented in conjunction with Susan Johnson's EFT approach, the couple was able to process the intensely emotional material with each other, develop mutual empathy, deepen their felt connection with each other, increase their sense of mutual respect, and increase their ability to engage in mutual affect regulation.

\section{Conclusion}

This example of couple's therapy, integrating mainstream approaches with a foundation of Gestalt theory and practice, shows that such work is not only possible, but can be very effective. There was no difficulty describing it as evidence-based practice for the purpose of third-party reimbursement, and it was easy to establish clear, concrete goals and interventions for treatment planning and billing. The couple found the integration of concrete goals and interventions helpful, in that it served to motivate them to work, since they had a clear sense of what they were working on, and how we were going to do it. This integration is also helpful to psychotherapy students and interns, who may feel intellectually attracted to Gestalt, but are intimidated or off-put by its lack of an objective and concrete stance in relation to either specific goals or interventions. They are often fearful that if they embrace Gestalt, they will be putting themselves outside the "mainstream" and thus taking a professional risk. They fear they will be unable to "defend" the practice, either within their agencies, or with third-party payers who are necessary for their income. In presenting Gestalt as a part of integrated practice, students find themselves more enthusiastic, more willing to experiment with it, and finally more able to embrace the fundamentally relativistic and subjective nature of couples work and couples functioning in the real world.

\section{References}

Backman, S., \& Wheeler, G. (1994). On Intimate Ground. San Francisco, CA: Jossey-Bass Publishers.

Basham, K. K., \& Miehls, D. (2004). Transforming the Legacy: Couple Therapy with Survivors of Childhood Trauma. New York, NY: Columbia University Press.

Bischof, G., \& Helmeke, K. (2003). Couple Therapy. In L. Hecker, \& J. Wetchler (Eds.), An Introduction to Marriage and Family Therapy (pp. 297-326). New York, NY: Haworth Press.

Borofsky, R., \& Borofsky, A. K. (1994). Giving and Receiving. In S. Backman, \& G. Wheeler, (Eds.), On Intimate Ground (pp.325-335). San Francisco, CA: Jossey-Bass Publishers. 
Briere, J. (2002). Treating Adult Survivors of Severe Childhood Abuse and Neglect: Further Development of an Integrative Model. In J. Myers, L. Berliner, J. Briere, C. Hendrix, T. Reid, \& C. Jenny (Eds.), The APSAC Handbook on Child Maltreatment (2nd ed., pp. 243-261). Newbury Park, CA: Sage Publications.

Clarkson, P., \& Mackewn, J. (1993). Key Figures in Counseling and Psychotherapy: Fritz Perls. Thousand Oaks, CA: Sage Publications.

Coleman, A. M. (1994). Companion Encyclopedia of Psychology (Vol. 2). New York, NY: Wiley \& Sons.

Courtois, C., \& Ford, J. (2009). Treating Complex Traumatic Stress Disorders. New York, NY: Guilford Press.

Drisko, J. (2004). Common Factors in Psychotherapy Outcome: Meta-Analytic Findings and Their Implications for Practice and Research. Families in Society, 85, 81-90. http://dx.doi.org/10.1606/1044-3894.239

Fisch, J. (2014). Couple Therapy with Survivors of Childhood Trauma. http://www.joanfisch.com/wpcontent/uploads/2012/01/CoupleTherapyChildhoodTrauma

Freud, S. (1920). A General Introduction to Psychoanalysis. New York, NY: Horace Liveright, Inc. http://dx.doi.org/10.1037/10667-000

Geib, P., \& Simon, S. (1994). Trauma Survivors and Their Partners: A Gestalt View. In S. Backman \& G. Wheeler (Eds.), On Intimate Ground. SanFrancisco, CA: Jossey-Bass Publishers.

Gergen, K. (1991). The Saturated Self: Dilemas of Identity in Contemporary Life. New York: Basic Books

Gergen, K. (2009). An Invitation to Social Construction (2nd ed.). Los Angeles, CA: Sage Publications.

Gergen, K. (2011). Relational Being: Beyond Self and Community. New York, NY: Oxford University Press. http://dx.doi.org/10.1093/acprof:osobl/9780199846269.001.0001

Gottman, J. (1999). The Marriage Clinic: A Scientifically Based Marital Therapy. New York: Norton \& Company.

Gurman, A. (Ed.) (2015). Clinical Handbook of Couple Therapy. New York: The Guilford Press.

Herman, J. (2009). Forward. In C. Courtois, \& J. Ford (Eds.), Treating Complex Traumatic Stress Disorders (pp. xiii-xvii). New York: Guilford Press.

Herman, A. (2013). The Cave and the Light: Plato versus Aristotle and the Struggle for the Soul of Western Civilization. New York: Random House.

Horrigan, P. (2007). Epistemology: An Introduction to the Philosophy of Knowledge. Lincoln, NE: iUniverse.

Hunt, M. (1993). The Story of Psychology. New York: Doubleday.

Johnson, S. (2002). Emotionally Focused Couple Therapy with Trauma Survivors: Strengthening Attachment Bonds. New York: Guilford Publications.

Johnson, S. (2009). Couple Therapy. In C. Courtois, \& J. Ford (Eds.), Treating Complex Traumatic Stress Disorders (pp. 371-390). New York: Guilford Press.

Kaufmann, G. (1989). The Psychology of Shame. New York: Springer.

Kepner, J. (1995). Healing Tasks: Psychotherapy with Adult Survivors of Childhood Abuse. San Francisco, CA: Jossey-Bass Inc.

Kerr, L. (2003). Childhood Traumas: An Outline and Overview. Focus, 1, 322-334.

Lee, R. (1994). Couple’s Shame: The Unaddressed Issue. In S. Backman, \& G Wheeler (Eds.), On Intimate Ground (pp. 262-290). San Francisco, CA. Jossey-Bass Publishers. 8

Lewis, B. (2009). Moving beyond Prozac, DSM, and the New Psychiatry: The Birth of Postpsychiatry. Ann Arbor, MI: University of Michigan Press.

Mazor, A. (2004). Relational Couple Therapy with Post-Traumatic Survivors: Links between Post-Traumatic Self and Contemporary Intimate Relationships. Contemporary Family Therapy, 26, 3-21. http://dx.doi.org/10.1023/B:COFT.0000016908.09501.bf

Parlett, M. (1991). Reflections on Field Theory. The British Gestalt Journal, 1, 68-91.

Saner, R. (1989). Culture Bias of Gestalt Therapy: Made-in-USA. The Gestalt Journal, 12, 57-73.

Schultz, D., \& Schultz, S. (2012). A History of Modern Psychology (10th ed.). Belmont, CA: Wadsworth.

Siegel, D. (1999). The Developing Mind: How Relationships and the Brain Interact to Shape Who We Are. New York: Guilford Press.

Siegel, D. (2007). The Mindful Brain: Reflection and Attunement in the Cultivation of Well-Being. New York: Norton \& Company.

Van der Kolk, B. et al. (1996a). Dissociation, Affect Dysregulation \& Somatization. American Journal of Psychiatry, 153, 83-93. 
Van der Kolk, B., McFarlane, A., \&Weisaeth, L. (Eds.) (1996b). Traumatic Stress: The Effects of Overwhelming Experience on Mind, Body, and Society. New York: Guilford Press.

Van der Kilk, B. (2014). The Body Keeps the Score: Brain, Mind, and Body in the Healing of Trauma. New York: Penguin Books.

Wheeler, G. (1991). Gestalt Reconsidered. New York: Gardner Press.

Wheeler, G. (2000). Beyond Individualism. Hillsdale: The Analytic Press.

Wiger, D., \& Harowski, K. (2003). Essentials of Crisis Counseling and Intervention. Hoboken, NJ: John Wiley \& Sons.

Woldt, A., \& Toman, S. (Eds.) (2005). Gestalt Therapy: History, Theory, and Practice. Thousand Oaks, CA: Sage Publications. http://dx.doi.org/10.4135/9781452225661

Zajonc, A. (1993). Catching the Light: The Entwined History of Light and Mind. New York: Oxford University Press. 